UNIFORM FIELD FRON DISTRIBUTION OF CURRENTS ON AN ELLIPSE

S. C. Snowdon

$\operatorname{March} 27,1968$

\title{
Purpose
}

To determine the distribution of currents on the surface of an ellipse that will produce a uniform field within the ellipse. Extention to a gradient field is also given.

Reference

3. W. R. Smythe, Static and Dynamic Electricity, McGrawHi.l1 Book Co., Inc., New York (1950).

Coordinate system

Conformal transformationsl suggest that the variables $(u, v)$ are useful when dealing with problems having an elliptical boundary.

$$
\mathrm{x}=\mathrm{a} \sin \mathrm{u} \operatorname{Ch} \mathrm{v} \quad \mathrm{y}=\mathrm{a} \cos \mathrm{u} \operatorname{sh} \mathrm{v}
$$

The factor for displacement is

$$
\mathrm{h}_{\mathrm{x}}=\mathrm{h}_{\mathrm{y}} \equiv \mathrm{h}=\mathrm{a} \sqrt{\operatorname{sh}^{2} \mathrm{v}+\cos ^{2} \mathrm{u}}
$$

Potentials (Uniform Field)

Since one desires a uniform inside the ellipse one chooses

$$
\Phi_{i}=-B_{C} \mathrm{y}=-\mathrm{B}_{0} \mathrm{a} \cos \mathrm{u} \operatorname{Sh} \mathrm{v}
$$

The transformation of Eq. (1), being conformal gives for the Laplace equation

$$
\frac{\partial^{2} \phi}{\partial u^{2}}+\frac{\partial^{2} \phi}{\partial v^{2}}=0 .
$$

A solution appropriate to the external region is

$$
B_{0}=A \text { a } \cos u e^{-v}
$$




\section{Boundary Conditions}

Th: normal component of the flux density is continuous.

This gives

$$
\left(\frac{\partial \Phi_{i}}{\partial v}\right)_{v=v_{0}}=\left(\frac{\partial \Phi_{0}}{\partial v}\right)_{v=v_{0}},
$$

where from Eq. (I) $\mathrm{v}=\mathrm{v}_{0}$ is seen to generate an ellipse. Thus

$$
A=B_{0} e^{v_{0}} \mathrm{Ch} v_{0}
$$

Applying the Ampere circuital law to a small region spanning $\mathrm{V}=\mathrm{v}_{0}$ and assuming a surface current of density $\sigma$ exists on the surface gives

$$
\left(H_{u 0}-H_{u i}\right)_{v}=v_{0} h \Delta u=4 \pi \sigma h \Delta u \text {. (emu) }
$$

or

$$
\sigma=\frac{I}{4 \pi}\left(\frac{\partial \Phi}{h \partial u}-\frac{\partial \phi_{0}}{h \partial u}\right) \quad v=v_{0}
$$

or

$$
\sigma=\frac{B_{0}}{4 \pi} \cdot e^{v_{0}} \cdot \frac{\operatorname{Sin} u}{\sqrt{\operatorname{Sh}^{2} v_{0}+\cos ^{2} u}} \quad(e m u)
$$

Potentials (Gradient Field)

One desires to have inside the ellipse

$$
\Phi_{i}=-B_{0}^{\prime} x y=-\frac{a^{2} B^{\prime} 0}{4} \sin 2 u \operatorname{sh} 2 v
$$

Outside the ellipse there are no sources. Hence

$$
\Phi_{0}=1 / 4 a^{2} A \sin 2 u e^{-2 v}
$$


Matching the normal fields on the elliptical boundary gives

$$
A=B^{\prime}{ }_{0} e^{2 v_{0}} \mathrm{Ch} 2 \mathrm{v}_{0} \text {. }
$$

The surface current density is then determined from the discontinuity in the tangential component of the field.

$$
\sigma=-\frac{a B^{\prime} \rho}{8 \pi} e^{2 v_{0}} \frac{\cos 2 u}{\sqrt{\operatorname{sh}^{2} v_{0}+\cos ^{2} u}} \quad(\mathrm{emu})
$$

